\title{
Design, Construction and Performance Evaluation of an Automatic Solar Tracker
}

\author{
M. M. H. Prodhan ${ }^{1}$, M. K. Hamid ${ }^{1}$, D. Hussain ${ }^{2}$, M. F. Huq ${ }^{1 *}$ \\ ${ }^{1}$ Department of Nuclear Engineering, University of Dhaka, Dhaka 1000, Bangladesh \\ ${ }^{2}$ Department of Applied Physics, Electronics and Communication Engineering, University of \\ Dhaka1000, Bangladesh
}

Received 13May 2015, accepted in final revised form 17October 2015

\begin{abstract}
In this research paper, an automatic solar tracker based on gear system is designed and developed. The solar tracker follows the sun from east to west during the day. Driving software has been developed using FLOWCODE and then it is burnt into the microcontroller (PIC 16F72). An intelligent sensor board followed by a sensor circuit has been used to sense the position of the sun.The system has been programmed to detect the intensity of sunlight by a differential arrangement of two LDRs and subsequently actuate the motor to position the solar panel where it can receive maximum sunlight. The solar tracking system is a mechatronic system that integrates electrical and mechanical systems and computer hardware \& software. The driving gear system and the structure of the PV module have been developed by using the locally available materials.In our research, the efficiency of this automatic solar tracker is $15 \%$ higher than the conventional tracker because of the designing automatic solar tracker and has got it successfully.This reveals that our system is compatible with the additional energy production.
\end{abstract}

Keywords: Renewable Energy; Power optimization; Automatic solar tracker; Maximum power capture; Closed-loop control.

๑) 2016 JSR Publications. ISSN: 2070-0237 (Print); 2070-0245 (Online). All rights reserved.

doi: http://dx.doi.org/10.3329/jsr.v8i1.23357 J. Sci. Res. 8(1), 1-12 (2016)

\section{Introduction}

Solar energy is the energy extracted from the rays issued from the sun in the form of heat and electricity. This energy is essential for all life on Earth. It is a renewable resource that is clean, economical, and has less pollution compared to other resources and energy [1-3]. The solar radiation consists of three parts. The direct radiation includes most of the energy. In non-concentrating flat-panel systems, the energy

*Corresponding author:fazlul.huq@du.ac.bd 
contributed by the direct beam sunlight drops off with the cosine of the angle between the incoming light and the panel. The reflectance (averaged across all polarizations) is approximately constant for angles of incidence up to around $50^{\circ}$, beyond which reflectance degrades rapidly. In Table 1 , direct power loss due to misalignment is shown where,

Loss $=1-\cos (i)$ [4]. Table1 describes the direct power loss due misalignment of PV panel.

Table 1. Direct power loss (\%) due to misalignment (incident angle i) [5]

\begin{tabular}{cccc}
\hline $\mathrm{i}$ & Loss [1-cos (i)] & $\mathrm{i}$ & Loss [1-cos (i)] \\
\hline $0^{\circ}$ & $0 \%$ & $15^{\circ}$ & $3.4 \%$ \\
$1^{\circ}$ & $0.015 \%$ & $30^{\circ}$ & $13.4 \%$ \\
$3^{\circ}$ & $0.14 \%$ & $45^{\circ}$ & $30 \%$ \\
$8^{\circ}$ & $1 \%$ & $60^{\circ}$ & $>50 \%$ \\
$23.4^{\circ}$ & $8.3 \%$ & $75^{\circ}$ & $>75 \%$ \\
\hline
\end{tabular}

A solar energy collecting surface performs best whenever it is faced to the sun. A majority of solar panels in use today are stationary and therefore do not give the maximum output of power that they can actually produce.To optimize the amount of energy received, a solar panel must be perpendicular to the light source; and since the sun moves both throughout the day as well as throughout the year, a solar panel needs to be able to follow the sun's movement to produce the maximum possible power [6]. The presence of a solar tracker is not essential for the operation of a solar panel, but without it, performance is reduced. Though solar trackers increase the energy harvesting; their cost, reliability, energy consumption, maintenance and performance are points to be considered.

An ideal tracker would allow the PV cell to accurately point towards the sun, compensating for both changes in the altitude angle of the sun to track the sun throughout the day, latitudinal offset of the sun during the seasonal change and changes in azimuth angle. Sun-tracking systems are usually classified into two categories: open looped or passive and close looped or active trackers [7]. Passive solar trackers, compared to active trackers, are less complex but work with low efficiency. Most of the active trackers are microprocessor and electro-optical sensor based, PC controlled date and time based, auxiliary bifacial solar cell based and a combination of these three systems.

Considering the movement capability, three main types of sun tracker can be found: fixed surfaces [8], single axis tracker [9] and dual axis tracker [10]. Single axis trackers usually use a polar mount for maximum solar efficiency [11]. In comparison with the single axis tracker, the dual axis tracker is complex and, therefore, expensive and also unreliable. Theoretically, $0-100 \%$ gain is achievable for two axis trackers [12]. Researchers have reported that changing the tilt angle to its daily and monthly optimum values throughout the year does not seem to be practical, another possibility, such as changing the tilt angle once in a season. On average for $6^{\circ}$ tilt angle summer 
months (Mar-Sep) and for $50^{\circ}$ tilt angle winter months (Oct-Feb) would give optimum results. Moreover, for seasonal tracking, Ghosh et al. [13] suggested changing the tilt angle $40^{\circ}$ once in a season. The result was evaluated for the city Dhaka and the study shows $>20 \%$ gain (annually) in the amount of solar radiation. Though double axis tracking mode or the polar axis tracking mode should be used when automatic tracking systems are available as the energy availability is much higher, the electricity generation of a photovoltaic system and the life cycle cost of tracking system have to be compared to determine if single or two axis tracking is feasible and practical.Solar tracking systems design has received considerable attention throughout the world in recent years [14,15].

This paper describes the design project that utilizes solar power to its full potential by tracking the sun throughout the day. The solar tracker follows the sun from east to west during the day. More energy is collected by controlling the solar panel to follow the sun. The system has been programmed to detect the intensity of sunlight by a differential arrangement of two photoresistors and subsequently actuate the motor to position the solar panel where it can receive maximum sunlight. The solar tracking system which we have implemented is the first tracking system of this kind in Bangladesh, and is implemented with only locally available equipment.

To extract several kilowatt from a PV module normally it needs more than eight panel having capacity of 55 watts of each panel. If each panel is of $5 \mathrm{~kg}$ weight, the total PV module produces a $40 \mathrm{~kg}$ weight. Therefore it needs to produce around $200 \mathrm{~N}$ $\mathrm{m}$ torque by the driving stepper motor [16]. A mechanical gear system has been used to magnify the holding torque [17-19] of a stepper motor having holding torque of $10 \mathrm{mN}-\mathrm{m}$ only. In this project it has been done successfully that holding torque of the motor has magnified by a tremendous factor of 1000 .

Another important point needs to be mentioned here thatthe used stepper motor has step angle of $2^{\circ}$. This step angle is further magnified at the PV module to more than that which creates a problem that PV module may not be right angle to the sun at all the time. The designed mechanical gear system also removes the problem because at the end gear of the complex gear system, step angle of the motor is converted to a lower value about $0.25^{\prime}$ [9]. This enables the PV module to remain always at right angle to the sun and the extracted power is always the maximum. And this amount is $20 \%$ higher than the conventional solar tracker [20].

In this paper, studies have been carried out to develop microcontroller based two solar trackers- first, a single axis tracker to track the sun throughout the day, from east to west, and later, the design was upgraded to include the execution of seasonal tracking too $[4,21]$. Such trackers are complex but provide high accuracy.

\section{Design and Construction}

Fig. 1 shows the system block diagram of designed automatic solar tracker. There are three different section in this designed system: Electronics section, Mechanical section 
and Software section. Electronic section is mainly consists of a sensor board followed by a sensor circuit and a microcontroller.

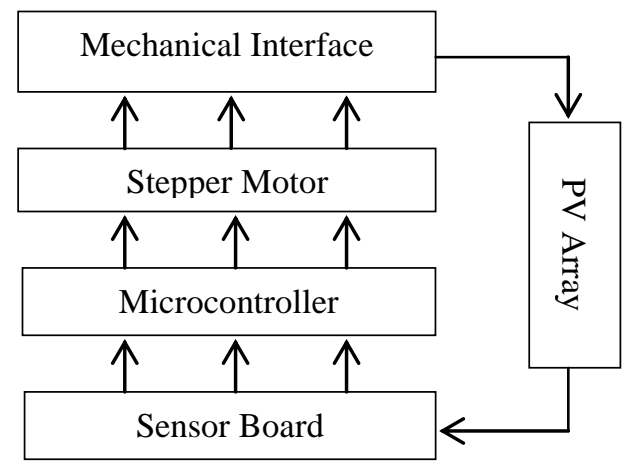

Fig. 1. System block diagram.

\subsection{Design of a working circuit}

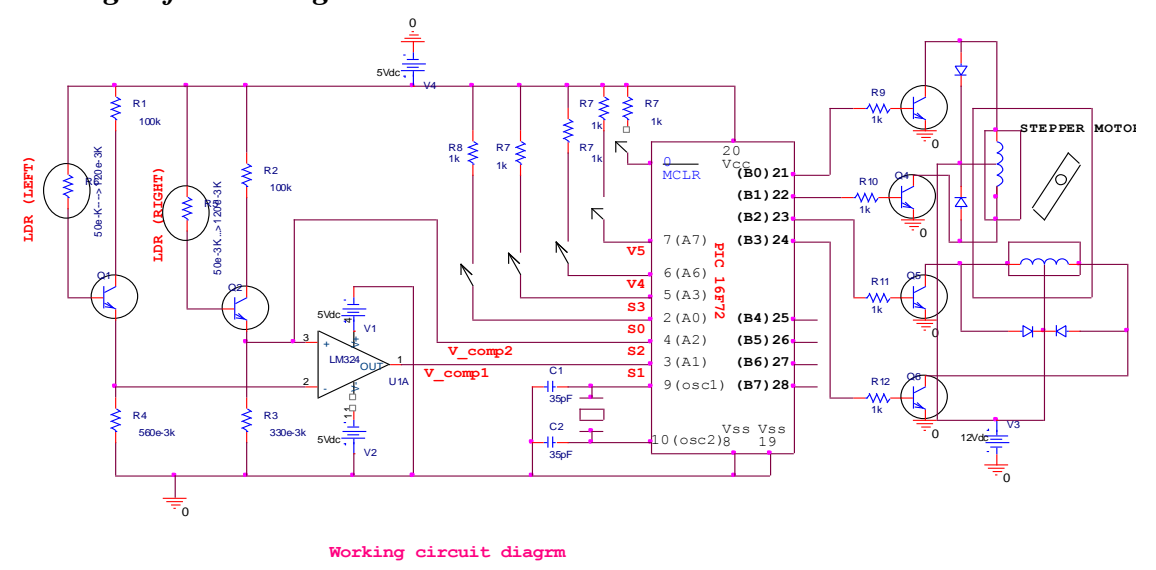

Fig. 2. Working circuit diagram.

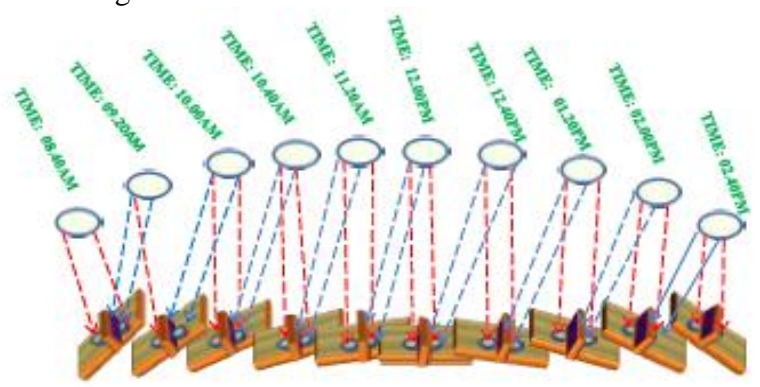

Fig. 3. Schematic diagram of continuous tracking. 


\subsection{Design of a gear system}

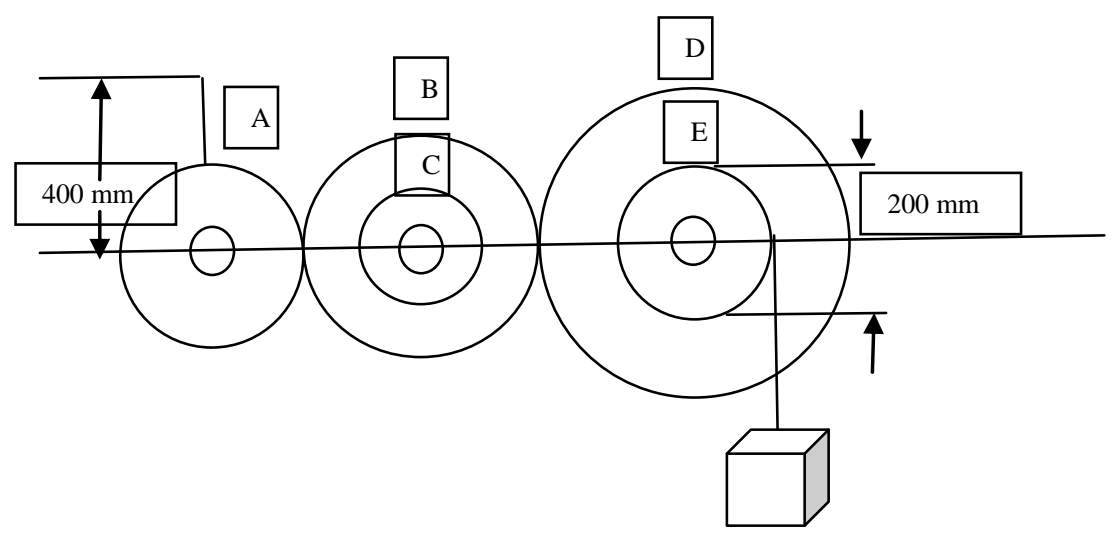

Fig. 4. Complex gear system.

Let,

Length of the handle $(\mathrm{l})=400 \mathrm{~mm}=0.4 \mathrm{~m}$;

Diameter of the drum $(d)=200 \mathrm{~mm}=$ or radius $(\mathrm{r})=0.1 \mathrm{~m}$;

No. of teeth of the wheel $A\left(T_{A}\right)=21 ; \quad$ No. of teeth of the wheel $B\left(T_{B}\right)=103$;

No. of teeth of the wheel $C\left(T_{C}\right)=21 ; \quad$ No. of teeth of the wheel $D\left(T_{D}\right)=103$;

Effort applied $(\mathrm{P})=10 \mathrm{~N}$ and $\mathrm{W}=$ Load that can be raised by the drum.

A little consideration will show that this example is exactly like that of a double purchase crap winch.

We know that velocity ratio of the system,

$$
\text { V.R. }=\frac{1}{r}\left(\frac{T_{B}}{T_{A}} \times \frac{T_{D}}{T_{C}}\right)=\frac{0.4}{0.1}\left(\frac{103}{21} \times \frac{103}{21}\right)=96.22
$$

Mechanical advantage $($ M.A $)=\frac{W}{P}=\frac{W}{10}$

And efficiency, $0.6=\frac{M \cdot A .}{V \cdot R}=\frac{\frac{W}{10}}{96.22}=\frac{W}{960.22}$

$\mathrm{W}=0.6 * 960.22=577.36 \mathrm{~N}$

\section{Increment of Holding Torque}

Given that the used motor holding torque is $\tau_{\mathrm{A}}=0.5 \mathrm{~N}-\mathrm{m}$. Therefore applied torque at gear $A$ is $0.5 \mathrm{~N}-\mathrm{m}$. And let us consider the pinion A revolves at $\mathrm{N}_{\mathrm{A}}=50 \mathrm{rev} / \mathrm{min}$. 
Thus, $N_{D}=\frac{{ }^{\tau} \mathrm{A}}{V_{R}}=\frac{21}{577.36}=0.0364 \mathrm{rev} / \mathrm{min}$

The input power, $P($ in $)=\frac{2 \Pi N_{A}}{60}=\frac{6 \times 50 \times 0.5}{60}=2.5 \mathrm{watt}$

Let the efficiency of the system is $75 \%$ then the output power, $P($ out $)=P($ in $) \times 0.75=2.5 \times 0.75=1.875$ watt

Now the torque gained at gear $\mathrm{D}$ can be calculated as

$\tau_{D}=\frac{60 \times P(\text { out })}{2 \Pi \times N_{D}}=\frac{60 \times 1.875}{6 \times 0.0364}=515.11 \mathrm{Nm}$

\subsection{Software Design of the system}

FOWCODE version 4 has been used to develop the driver software. FLOWCODE is a very high level programming system for PIC micros. In addition, it is one of the most advanced graphical programming languages for microcontroller [22]. When the code is written graphically, it can be compiled to C, then ASM and then HEX file. With the help of microcontroller burner, the converted HEX file is burned/programmed to the microcontroller and the programmed microcontrolleris then ready for use. A flowchart to run the proposed system is shown in the Fig. 5.

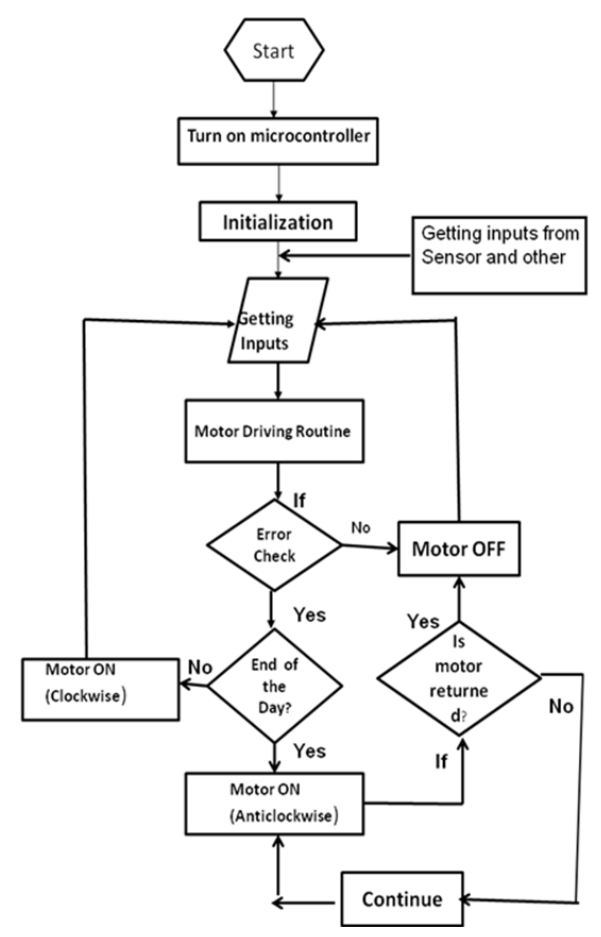

Fig. 5. Flowchart of the program. 


\subsection{Construction of the system}
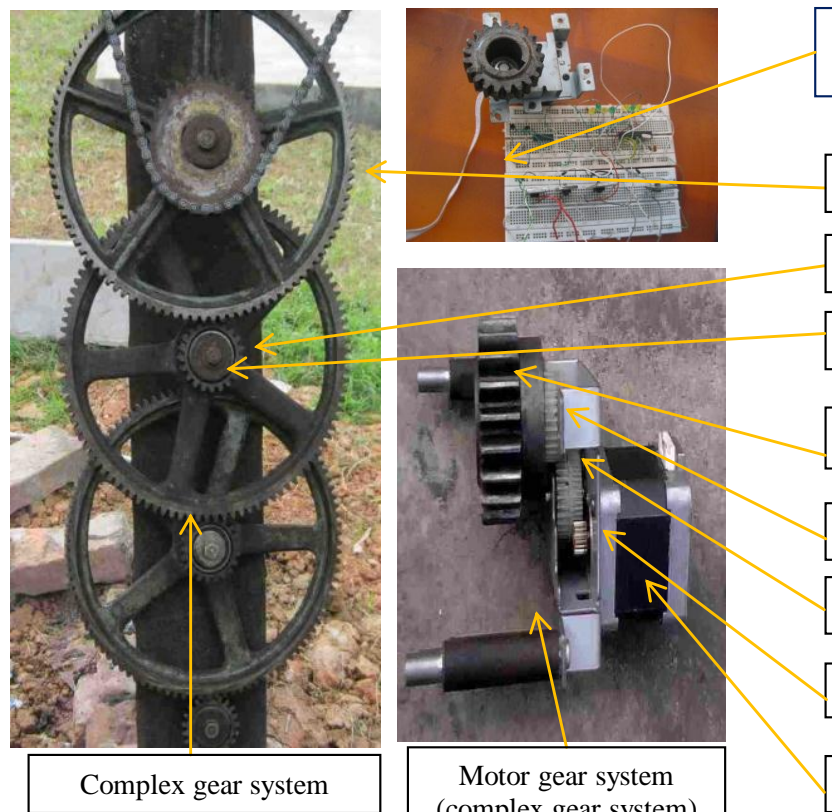

Stepper motor with sensor
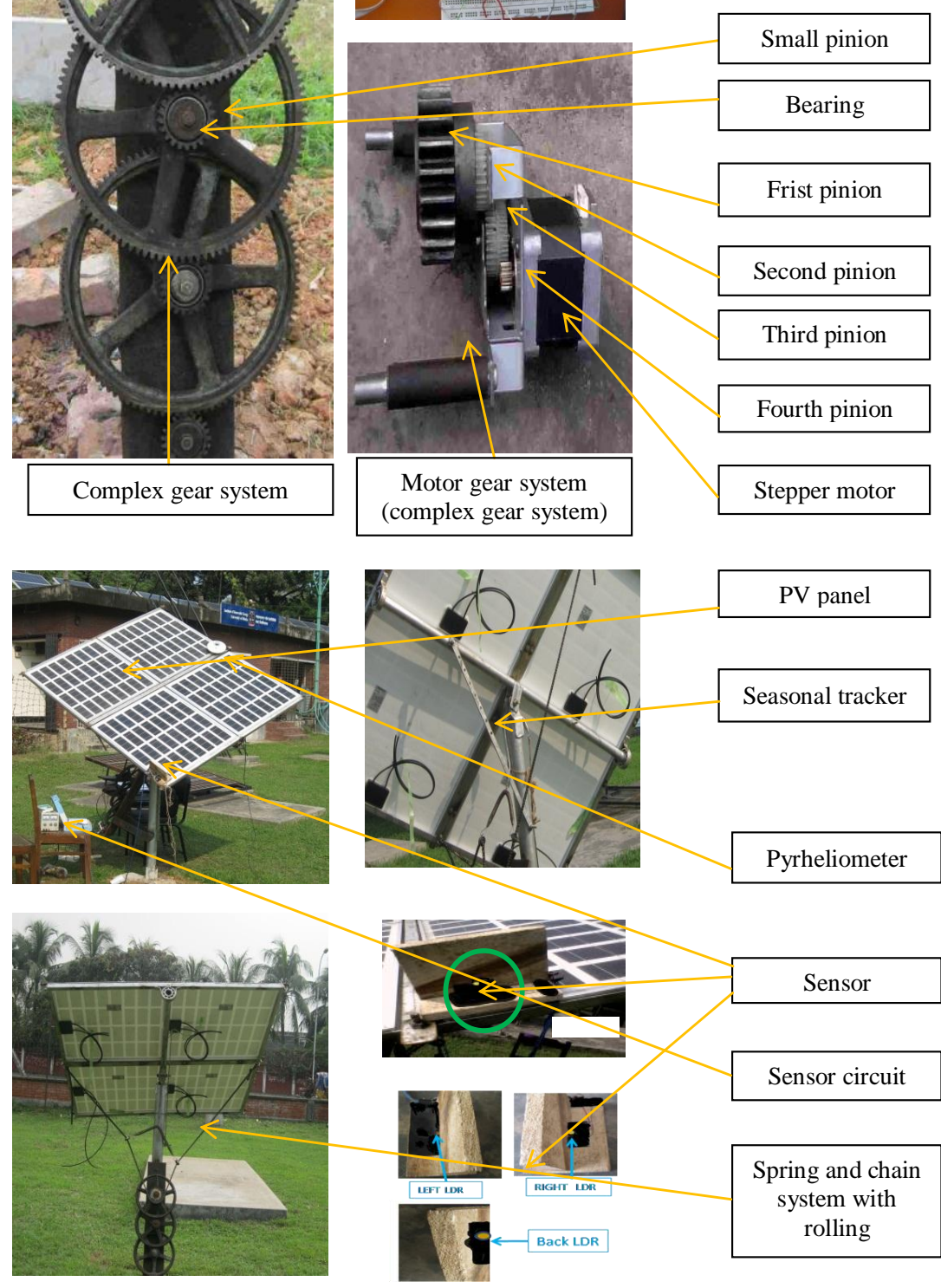

Sensor circuit

Spring and chain system with rolling

Fig. 6. Construction of an automatic solar tracker. 


\section{Results and Discussion}

Table 2. Data for current, voltage and radiation with tracking on $22^{\text {nd }}$ November 2011.

\begin{tabular}{|c|c|c|c|c|c|c|}
\hline Time & $\begin{array}{l}\text { Pyrhelio } \\
\text { meter } \\
\text { Reading } \\
(\mathrm{mV})\end{array}$ & $\begin{array}{l}\text { Intensity } \\
\left(w^{-2}\right)\end{array}$ & $\begin{array}{l}\text { Single } \\
\text { panel } \\
\text { Current } \\
\text { (A) }\end{array}$ & $\begin{array}{l}\text { Single } \\
\text { panel } \\
\text { voltage } \\
(\mathrm{V})\end{array}$ & $\begin{array}{l}\text { Single panel } \\
\text { power with } \\
\text { tracking } \\
\text { (W) }\end{array}$ & $\begin{array}{l}4 \text { panel power } \\
\text { with tracking } \\
\text { (WH) }\end{array}$ \\
\hline $8: 40$ & 3.4 & 607.1428571 & 2.4 & 17.45 & 41.88 & 27.80832 \\
\hline $8: 50$ & 3.4 & 607.1428571 & 2.43 & 17.48 & 42.4764 & 28.20433 \\
\hline 9:00 & 3.5 & 625 & 2.44 & 17.4 & 42.456 & 28.19078 \\
\hline $9: 10$ & 3.6 & 642.8571429 & 2.47 & 17.49 & 43.2003 & 28.685 \\
\hline $9: 20$ & 3.6 & 642.8571429 & 2.48 & 17.48 & 43.3504 & 28.78467 \\
\hline $9: 30$ & 3.5 & 625 & 2.5 & 17.53 & 43.825 & 29.0998 \\
\hline $9: 40$ & 3.6 & 642.8571429 & 2.53 & 17.55 & 44.4015 & 29.4826 \\
\hline $9: 50$ & 3.6 & 642.8571429 & 2.57 & 17.56 & 45.1292 & 29.96579 \\
\hline $10: 00$ & 3.6 & 642.8571429 & 2.59 & 17.56 & 45.4804 & 30.19899 \\
\hline $10: 10$ & 3.5 & 625 & 2.65 & 17.42 & 46.163 & 30.65223 \\
\hline $10: 20$ & 3.6 & 642.8571429 & 2.72 & 17.44 & 47.4368 & 31.49804 \\
\hline $10: 30$ & 3.6 & 642.8571429 & 2.77 & 17.46 & 48.3642 & 32.11383 \\
\hline $10: 40$ & 3.7 & 660.7142857 & 2.8 & 17.39 & 48.692 & 32.33149 \\
\hline $10: 50$ & 3.8 & 678.5714286 & 2.86 & 17.37 & 49.6782 & 32.98632 \\
\hline 11:00 & 3.9 & 696.4285714 & 2.89 & 17.33 & 50.0837 & 33.25558 \\
\hline $11: 10$ & 3.9 & 696.4285714 & 2.93 & 17.32 & 50.7476 & 33.69641 \\
\hline $11: 20$ & 3.9 & 696.4285714 & 2.9 & 17.26 & 50.054 & 33.23586 \\
\hline $11: 30$ & 3.85 & 687.5 & 2.8 & 17.28 & 48.384 & 32.12698 \\
\hline $11: 40$ & 3.8 & 678.5714286 & 2.94 & 17.28 & 50.8032 & 33.73332 \\
\hline $11: 50$ & 3.8 & 678.5714286 & 2.96 & 17.29 & 51.1784 & 33.98246 \\
\hline $12: 00$ & 3.75 & 669.6428571 & 2.97 & 17.36 & 51.5592 & 34.23531 \\
\hline $1: 00$ & 3.8 & 678.5714286 & 2.98 & 17.35 & 51.703 & 34.33079 \\
\hline $1: 10$ & 3.81 & 680.3571429 & 2.98 & 17.37 & 51.7626 & 34.37037 \\
\hline $1: 20$ & 3.82 & 682.1428571 & 3 & 17.39 & 52.17 & 34.64088 \\
\hline $1: 30$ & 3.8 & 678.5714286 & 3 & 17.39 & 52.17 & 34.64088 \\
\hline $1: 40$ & 3.9 & 696.4285714 & 3.4 & 17.41 & 59.194 & 39.30482 \\
\hline $1: 50$ & 3.9 & 696.4285714 & 3.5 & 17.44 & 61.04 & 40.53056 \\
\hline $2: 00$ & 4 & 714.2857143 & 3.3 & 17.5 & 57.75 & 38.346 \\
\hline $2: 10$ & 3.7 & 660.7142857 & 3 & 17.4 & 52.2 & 34.6608 \\
\hline $2: 20$ & 3.7 & 660.7142857 & 2.9 & 17.36 & 50.344 & 33.42842 \\
\hline $2: 30$ & 3.6 & 642.8571429 & 2.7 & 17.4 & 46.98 & 31.19472 \\
\hline $2: 40$ & 3.6 & 642.8571429 & 2.67 & 17.41 & 46.4847 & 30.86584 \\
\hline $2: 50$ & 3.7 & 660.7142857 & 2.58 & 17.42 & 44.9436 & 29.84255 \\
\hline $3: 00$ & 3.6 & 642.8571429 & 2.56 & 17.41 & 44.5696 & 29.59421 \\
\hline $3: 10$ & 3.5 & 625 & 2.53 & 17.5 & 44.275 & 29.3986 \\
\hline $3: 20$ & 3.5 & 625 & 2.45 & 17.55 & 42.9975 & 28.55034 \\
\hline $3: 30$ & 3.5 & 625 & 2.41 & 17.56 & 42.3196 & 28.10021 \\
\hline
\end{tabular}




\begin{tabular}{lllllll}
\hline & $\begin{array}{l}\text { Pyrhelio } \\
\text { meter } \\
\text { Reading } \\
(\mathrm{mV})\end{array}$ & $\begin{array}{l}\text { Intensity } \\
\left(\mathrm{wm}^{-2}\right)\end{array}$ & $\begin{array}{l}\text { Single } \\
\text { panel } \\
\text { Current } \\
(\mathrm{A})\end{array}$ & $\begin{array}{l}\text { Single } \\
\text { panel } \\
\text { voltage } \\
(\mathrm{V})\end{array}$ & $\begin{array}{l}\text { Single panel } \\
\text { power with } \\
\text { tracking } \\
(\mathrm{W})\end{array}$ & $\begin{array}{l}\text { 4 panel power } \\
\text { with tracking } \\
(\mathrm{WH})\end{array}$ \\
\hline $3: 40$ & 3.4 & 607.1428571 & 2.4 & 17.46 & 41.904 & 27.82426 \\
$3: 50$ & 3.45 & 616.0714286 & 2.37 & 17.43 & 41.3091 & 27.42924 \\
$4: 00$ & 3.35 & 598.2142857 & 2.28 & 17.42 & 39.7176 & 26.37249 \\
$4: 10$ & 3.34 & 596.4285714 & 2.23 & 17.45 & 38.9135 & 25.83856 \\
$4: 20$ & 3.3 & 589.2857143 & 2.21 & 17.41 & 38.4761 & 25.54813 \\
$4: 30$ & 3.2 & 571.4285714 & 2.17 & 17.39 & 37.7363 & 25.0569 \\
$4: 40$ & 3.1 & 553.5714286 & 2.1 & 17.47 & 36.687 & 24.36017 \\
$4: 50$ & 3 & 535.7142857 & 2.12 & 17.47 & 37.0364 & 24.59217 \\
$5: 00$ & 2.9 & 517.8571429 & 1.8 & 17.48 & 31.464 & 20.8921 \\
\hline Total Power with Auto Tracking System $=$ & & & 1413.982
\end{tabular}

Table 3.Data for current, voltage \& radiation without tracking on $23^{\text {rd }}$ November 2011.

\begin{tabular}{|c|c|c|c|c|c|c|}
\hline Time & $\begin{array}{l}\text { Pyrhelio } \\
\text { meter } \\
\text { Reading } \\
(\mathrm{mV})\end{array}$ & $\begin{array}{l}\text { Intensity } \\
\left(\mathrm{Wm}^{-2}\right)\end{array}$ & $\begin{array}{l}\text { Single } \\
\text { panel } \\
\text { Current( } \\
\text { A) } \\
\end{array}$ & $\begin{array}{l}\text { Single } \\
\text { panel } \\
\text { voltage } \\
\text { (V) }\end{array}$ & $\begin{array}{l}\text { Single panel } \\
\text { power without } \\
\text { tracking }(\mathrm{W})\end{array}$ & $\begin{array}{l}4 \text { panel power } \\
\text { without } \\
\text { tracking (WH) }\end{array}$ \\
\hline $8: 40$ & 3.4 & 607.1428571 & 2.1 & 17.05 & 35.805 & 23.77452 \\
\hline $8: 50$ & 3.4 & 607.1428571 & 2.15 & 17.1 & 36.765 & 24.41196 \\
\hline 9:00 & 3.5 & 625 & 2.21 & 17.28 & 38.1888 & 25.35736 \\
\hline $9: 10$ & 3.6 & 642.8571429 & 2.23 & 17.3 & 38.579 & 25.61646 \\
\hline $9: 20$ & 3.6 & 642.8571429 & 2.26 & 17.41 & 39.3466 & 26.12614 \\
\hline $9: 30$ & 3.5 & 625 & 2.27 & 17.43 & 39.5661 & 26.27189 \\
\hline 9:40 & 3.6 & 642.8571429 & 2.31 & 17.55 & 40.5405 & 26.91889 \\
\hline 9:50 & 3.6 & 642.8571429 & 2.37 & 17.5 & 41.475 & 27.5394 \\
\hline 10:00 & 3.6 & 642.8571429 & 2.39 & 17.54 & 41.9206 & 27.83528 \\
\hline 10:10 & 3.5 & 625 & 2.41 & 17.42 & 41.9822 & 27.87618 \\
\hline $10: 20$ & 3.6 & 642.8571429 & 2.46 & 17.44 & 42.9024 & 28.48719 \\
\hline $10: 30$ & 3.6 & 642.8571429 & 2.46 & 17.46 & 42.9516 & 28.51986 \\
\hline 10:40 & 3.7 & 660.7142857 & 2.47 & 17.39 & 42.9533 & 28.52099 \\
\hline $10: 50$ & 3.8 & 678.5714286 & 2.6 & 17.37 & 45.162 & 29.98757 \\
\hline 11:00 & 3.9 & 696.4285714 & 2.64 & 17.33 & 45.7512 & 30.3788 \\
\hline 11:10 & 3.9 & 696.4285714 & 2.65 & 17.32 & 45.898 & 30.47627 \\
\hline $11: 20$ & 3.9 & 696.4285714 & 2.7 & 17.26 & 46.602 & 30.94373 \\
\hline $11: 30$ & 3.85 & 687.5 & 2.77 & 17.28 & 47.8656 & 31.78276 \\
\hline 11:40 & 3.8 & 678.5714286 & 2.7 & 17.28 & 46.656 & 30.97958 \\
\hline $11: 50$ & 3.8 & 678.5714286 & 2.72 & 17.29 & 47.0288 & 31.22712 \\
\hline 12:00 & 3.75 & 669.6428571 & 2.76 & 17.36 & 47.9136 & 31.81463 \\
\hline 1:00 & 3.8 & 678.5714286 & 2.7 & 17.35 & 46.845 & 31.10508 \\
\hline $1: 10$ & 3.81 & 680.3571429 & 2.68 & 17.37 & 46.5516 & 30.91026 \\
\hline 1:20 & 3.82 & 682.1428571 & 2.72 & 17.39 & 47.3008 & 31.40773 \\
\hline $1: 30$ & 3.8 & 678.5714286 & 2.6 & 17.39 & 45.214 & 30.0221 \\
\hline $1: 40$ & 3.9 & 696.4285714 & 2.5 & 17.41 & 43.525 & 28.9006 \\
\hline
\end{tabular}




\begin{tabular}{|c|c|c|c|c|c|c|}
\hline Time & $\begin{array}{l}\text { Pyrhelio } \\
\text { meter } \\
\text { Reading } \\
(\mathrm{mV})\end{array}$ & $\begin{array}{l}\text { Intensity } \\
\left(\mathrm{Wm}^{-2}\right)\end{array}$ & $\begin{array}{l}\text { Single } \\
\text { panel } \\
\text { Current } \\
\text { (A) } \\
\end{array}$ & $\begin{array}{l}\text { Single } \\
\text { panel } \\
\text { voltage } \\
(\mathrm{V}) \\
\end{array}$ & $\begin{array}{l}\text { Single panel } \\
\text { power without } \\
\text { tracking }(\mathrm{W})\end{array}$ & $\begin{array}{l}4 \text { panel power } \\
\text { without } \\
\text { tracking }(\mathrm{WH})\end{array}$ \\
\hline $1: 50$ & 3.9 & 696.4285714 & 2.54 & 17.44 & 44.2976 & 29.41361 \\
\hline 2:00 & 4 & 714.2857143 & 2.63 & 17.5 & 46.025 & 30.5606 \\
\hline $2: 10$ & 3.7 & 660.7142857 & 2.58 & 17.4 & 44.892 & 29.80829 \\
\hline $2: 20$ & 3.7 & 660.7142857 & 2.6 & 17.36 & 45.136 & 29.9703 \\
\hline $2: 30$ & 3.6 & 642.8571429 & 2.57 & 17.4 & 44.718 & 29.69275 \\
\hline $2: 40$ & 3.6 & 642.8571429 & 2.3 & 17.41 & 40.043 & 26.58855 \\
\hline $2: 50$ & 3.7 & 660.7142857 & 2.34 & 17.42 & 40.7628 & 27.0665 \\
\hline 3:00 & 3.6 & 642.8571429 & 2.3 & 17.41 & 40.043 & 26.58855 \\
\hline $3: 10$ & 3.5 & 625 & 2.29 & 17.4 & 39.846 & 26.45774 \\
\hline $3: 20$ & 3.5 & 625 & 2.2 & 17.35 & 38.17 & 25.34488 \\
\hline 3:30 & 3.5 & 625 & 2.18 & 17.3 & 37.714 & 25.0421 \\
\hline $3: 40$ & 3.4 & 607.1428571 & 2.1 & 17.1 & 35.91 & 23.84424 \\
\hline $3: 50$ & 3.45 & 616.0714286 & 2 & 17 & 34 & 22.576 \\
\hline 4:00 & 3.35 & 598.2142857 & 2 & 16.8 & 33.6 & 22.3104 \\
\hline $4: 10$ & 3.34 & 596.4285714 & 1.9 & 16.75 & 31.825 & 21.1318 \\
\hline $4: 20$ & 3.3 & 589.2857143 & 1.8 & 16.56 & 29.808 & 19.79251 \\
\hline 4:30 & 3.2 & 571.4285714 & 1.7 & 16.7 & 28.39 & 18.85096 \\
\hline $4: 40$ & 3.1 & 553.5714286 & 1.6 & 16.5 & 26.4 & 17.5296 \\
\hline 4:50 & 3 & 535.7142857 & 1.5 & 16.43 & 24.645 & 16.36428 \\
\hline 5:00 & 2.9 & 517.8571429 & 1.5 & 16.35 & 24.525 & 16.2846 \\
\hline
\end{tabular}

Total Power without Auto Tracking System =

1232.411

Power Calculation from Table 2 and Table 3:

Power without tracking $=1232.411 \mathrm{WH} \approx 1232 \mathrm{WH}$

Power with tracking $=1413.982 \mathrm{WH} \approx 1414 \mathrm{WH}$

Extra power for tracking, $=(1414-1232) \mathrm{WH}=182 \mathrm{WH}$

Increased power $=\frac{1414-1232}{1232} \times 100 \% \approx 15 \%$

\subsection{Load Calculation:}

If each panel capacity is 55 watt then 4 panel capacities are 220 watt. Since we have designed an automatic solar tracker, using that it will be possible to keep the solar panel always perpendicular to the sun thus the proposed system supplies always around $220 \mathrm{~W}$ rather than around $165 \mathrm{~W}$. 


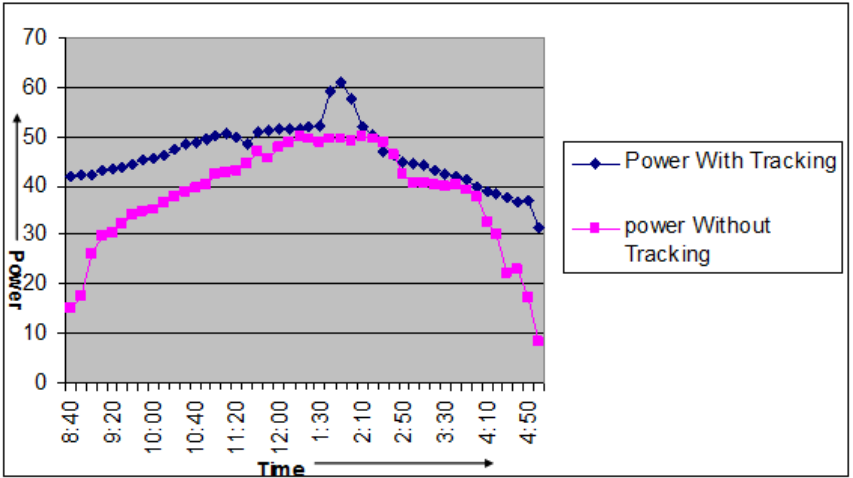

Fig. 7. Power versus time plot.

As the meters always fluctuate so average reading is taken. The data are taking simultaneously with tracking and without tracking. The power due to tracking sufficiently increase compared to without tracking.

\section{Conclusion}

An automatic solar tracker has been designed and implemented successfully and it is claimed that this research is successful in increasing the output from the solar panel up to $15 \%$.Extra power extracted from the panel with tracker is $182 \mathrm{~W}$. It is to be noted that in the summer season, this percentage of extra power will increase up to 30\%.The other goal of the system is to provide economic benefit to its users. Previously designed all the systems for solar automatic tracker are imported which is very costly. But our system is designed locally at a relatively lower cost.

\section{Acknowledgment}

The authors would like to thank Dr. Md. Habibur Rahman, Professor, Department of Electrical and Electronic Engineering, University of Dhaka and Dr. Md. Saiful Huque, Director, Institute of Energy, University of Dhaka for their carefulguide. Authors would also like to thank the Authority of Institute of Energy,University of Dhaka for construction of this Automatic Solar Tracker in its Premises.

\section{References}

1. A. Zahedi, Humans, Inform. Technol.3, 2692 (1994).

2. B. Ahmmad, Y. Kitamura, Y. Kusumoto, H. Yang, and M. Abdulla-Al-Mamun, J. Sci. Res. 2(1), 1 (2010). http://dx.doi.org/10.3329/jsr.v2i1.2660

3. B. Ahmmad, Y. Kusumoto, M. Abdulla-Al-Mamun, A. Mihata, and H. Yang, J. Sci. Res. 1(3), 430 (2009). http://dx.doi.org/10.3329/jsr.v1i3.2631

4. M. E. Haque, E. Asief, R. M. T. Islam, A. B. Ahsan, and R. Islam, B. Eng. thesis, Ahsanullah University of Science and Technology, Dhaka, Bangladesh (2011).

5. Basic concept of solar tracker, http://en.wikipedia.org/wiki/Solar_tracker 
6. M. B. Oumarou, A. A. Toyin, and F. A. Oluwole, Sustainable Energy 3(1), 9 (2015).

7. C. Lee, P. Chou, C. Chiang, and C. Lin, Sensors 9, 3875 (2009). http://dx.doi.org/10.3390/s90503875

8. N. H. Helwa, A. B. G. Bahgat, A. M. R. E. Shafee, and E. T. E.Shanawy, Energy Sources $22(2000)$.

9. V. Poulek and M. A. Libra, Solar Energy Mater. Solar Cells 60, 99 (2000). http://dx.doi.org/10.1016/S0927-0248(99)00071-9

10. S. Abdallah and N. Salem, Energy Conversion and Management 45(11), 1931 (2004). http://dx.doi.org/10.1016/j.enconman.2003.10.007

11. S. Rana, Int. J. Tech. Res. Appl. 1(4), 77 (2013).

12. Tracstar (2007) [Online]. Available at: http://www.helmholz.us/smallpowersystems/Intro.pdf

13. H.R. Ghosh, N.C. Bhowmik, and M. Hussain, Renewable Energy 35, 1292 (2010).

14. O. M. Ben and A. T. Abdulrahim, in Design and Testing of a Low Cost Single Axis Solar Tracker - Proc. of the 30th Int. Conf. on Solid Waste Technol. and Management (Philadelphia, USA, 2015) pp. 926-936.

15. S.M.Ali, P. Mohapatra, and A. Pradhan, Int. J. Eng. Res. Dev. 4(8), 64 (2012).

16. Lecture 15, Torque, Center of Gravity, Rotational Equilibrium, http://rockpile.phys.virginia.edu/arch15.pdf

17. J. Damm, Issue \#17, An Active Solar Tracking System, HomeBrew Magazine (1990).

18. R. Singh and Y.R. Sood - IEEE Conf. (TENCON, Singapore, 2009) 1.

19. J. Arai, K. Iba, T. Funabashi; Y. Nakanishi, K. Koyanagi, and R.Yokoyama, IEEE Circuits Syst. Magazine 8(3), 52 (2008). http://dx.doi.org/10.1109/MCAS.2008.928420

20. Nupur, Neha, Sangagiri, S. Mishra, and G. K. Dubey, Int. J. Adv. Res. Electrical, Electronics and Instrumentation Eng. 2(5), 1880 (2013).

21. E. Basher, M. H. Tania, and S. Alam, in A Microcontroller Based Automatic Solar Tracking - Proc. ICETCESD (2011) 11, pp. 384.

22. Matrix Multimedia - FlowcodeGraphical Programming Languages. www.matrixmultimedia.com/flowcode.php 